\title{
Reprovação escolar no Brasil: história da configuração de um problema político-educacional $^{*}$
}

\author{
NATÁLIA DE LACERDA GIL \\ Universidade Federal do Rio Grande do Sul, Porto Alegre, RS, Brasil
}

\section{RESUMO}

O presente artigo busca argumentar que o movimento dos alunos pela escola obrigatória brasileira somente adquire feição de problema político educacional a partir dos anos 1930. Nesse sentido, ressalta que o sentido atual da noção de reprovação se define apenas no século XX, embora fosse possível reprovar os alunos desde antes. Pretende mostrar, ainda, que, em articulação com mudanças políticas e culturais em educação - como a afirmação da escola obrigatória, a definição do modelo escolar seriado e a primazia da homogeneidade das classes -, a existência de estatísticas sistemáticas e de melhor qualidade, após 1931, contribuiu decisivamente para a definição das condições de possibilidade da inclusão na agenda política da reprovação como problema.

\section{PALAVRAS-CHAVE}

história da educação; estatísticas de educação; rendimento escolar; política educacional.

* Este artigo é resultado do projeto interinstitucional (UFRGS, UNICAMP, USP) "A escola obrigatória e seus alunos: acesso, permanência e desempenhos (1870-1970)", financiado pelo CNPq (processo no 454937/2014-8). Uma versão preliminar deste trabalho foi apresentada na 37a Reunião Nacional da Anped (Florianópolis, 2015). 


\title{
STUDENT FAILURE IN BRAZIL: THE HISTORY \\ OF THE CONFIGURATION OF A POLITICAL AND EDUCATIONAL PROBLEM
}

\begin{abstract}
The present article intends to propose the argumentation that the movement of students by Brazilian mandatory school only acquires signs of educational political problem from the 1930's on. It indicates that the current sense of the notion of student failure is defined only in the XX century, although it was possible to fail students since before. It intends to show further that, in articulation with political and cultural changes in education - as the statement of the compulsory school, the definition of school grades model and the primacy of the homogeneity of classes the existence of better statistics and systematic ones after 1931 decisively contributed in defining the conditions for the possibility of inclusion, on the political agenda, of student failure as a problem.
\end{abstract}

\section{KEYWORDS}

history of education; education statistics; school performance; educational politics.

\section{LA REPROBACIÓN ESCOLAR EN BRASIL: HISTORIA DE LA CONFIGURACIÓN DE UN PROBLEMA POLÍTICO EDUCACIONAL}

\section{RESUMEN}

El artículo busca argumentar que el movimiento de los estudiantes en la escuela obligatoria brasileña solo adquiere característica de problema político educativo a partir de los años 1930. Indica que el sentido en curso de la noción de reprobación solo es definido en el siglo XX, aunque fuera posible reprobar los estudiantes desde antes. Muestra, también, que en articulación con los cambios políticos y culturales en educación - como la afirmación de la escuela obligatoria, la definición del modelo graduado y la primacía de la homogeneidad de las clases - la existencia de estadísticas sistemáticas y de mejor calidad, después de 1931, contribuyó contundentemente en la definición de las condiciones de posibilidad de la inclusión en la agenda política de la reprobación como problema.

\section{PALABRAS CLAVE}

historia de la educación; estadísticas de educación; rendimiento escolar; política educativa. 
Ao examinar as estatísticas escolares entre 1930 e 1971, Romanelli (1978) indicava que a expansão da escola, nesse período, evidenciou uma "oferta insuficiente", um "baixo rendimento interno" e uma notável "discriminação social". Isso decorria da compreensão de que a ampliação das matrículas foi significativa nessas décadas, mas não chegava a oferecer vagas a todas as crianças em idade de frequentar a escola; dos alunos matriculados na $1^{\mathrm{a}}$ série do ensino primário, poucos chegavam às séries seguintes, abandonando a instituição ao longo do percurso; e a reprovação e o abandono dos estudos eram mais acentuados entre os alunos oriundos das camadas populares.

Em consonância com essas análises, interessada em compreender os processos de discriminação social no interior da escola e comprometida com a crítica ao papel assumido pela psicologia escolar na legitimação desse processo discriminatório, Maria Helena de Souza Patto defendia, em 1987, a tese que resultou no livro A produção do fracasso escolar. Nessa pesquisa, a autora conseguia mostrar que o baixo desempenho escolar das crianças pobres era engendrado por mecanismos seletivos internos à dinâmica institucional, e não decorrente de deficiências cognitivas dos educandos, nem do déficit ou da diferença cultural. Patto (1993, p. 346) indicava, ainda, que a pesquisa permitia compreender que "o fracasso da escola elementar é administrado por um discurso científico que, escudado em sua competência, naturaliza esse fracasso aos olhos de todos os envolvidos no processo".

A presença de estatísticas mais detalhadas sobre a reprovação e a evasão escolar e o debate educacional, que apresentava a questão como uma séria distorção da escola brasileira, conduziram a algumas ações políticas que visavam a apresentar soluções. Assim, foram propostas diferentes iniciativas, como o ciclo básico, as classes de aceleração e as aulas de reforço escolar, por exemplo. Jacomini (2010, p. 22) menciona que

Embora a discussão sobre políticas de não reprovação anual tenham ocorrido no Brasil desde a década de 1920, foi somente a partir da década de 1960 que algumas redes públicas de ensino municipal e estadual organizaram o ensino de forma não seriada e adotaram políticas de não reprovação anual.

A autora acrescenta que, "de modo geral, as propostas de organização do ensino em ciclos surgiram da necessidade de se buscarem alternativas para enfrentar os altos índices de reprovação e evasão escolares e construir uma escola menos seletiva e excludente" (Jacomini, 2010, p. 22).

Contudo, é forçoso admitir que a ocorrência da reprovação dos alunos já existia muito antes. Desde a instalação da escola moderna no Brasil, ainda no período colonial, está previsto que os estudantes se submetam aos exames, nos quais podem ser aprovados ou reprovados. A noção de repetência propriamente, no entanto, tem condições de surgir apenas quando se institui a escola seriada, no final do século XIX.É a partir da existência da separação física dos alunos de acordo com as séries indicadas nos programas de ensino, ao lado da adoção do ensino simultâneo, que se torna necessário que, ao final de um ano letivo, aqueles que não apresentam aprendizagem correspondente aos mínimos esperados, em termos de domínio do programa da série frequentada, voltem a cursá-la desde o início no ano seguinte, ou seja, que repitam a mesma série. 
Portanto, não eram compreendidos necessariamente como problemas político-educacionais eventos tais como a existência de alunos que não aprendiam no ritmo esperado as matérias previstas no programa, o fato de que continuassem na escola por mais tempo até que ficasse evidente o domínio dos conteúdos curriculares, a ocorrência de que deixassem de frequentar a escola tão logo eles próprios ou suas famílias achassem que já tinham aprendido o suficiente ou que não iriam mesmo avançar mais nas aprendizagens. Essas ocorrências serão assumidas como distorções da trajetória dos estudantes apenas mais tarde. Interessa, portanto, localizar e compreender o período em que esses eventos são mobilizados como problema no discurso educacional, nos discursos especializados (de pediatras e psicólogos, por exemplo) e nos discursos políticos.

Neste artigo pretendo inicialmente tecer algumas considerações teórico-metodológicas no que se refere à compreensão acerca das estatísticas e das palavras que elas mobilizam. Indico, ainda, a conceituação utilizada sobre o que se estabelece como problema na agenda política. Apresento, na sequência, uma breve discussão sobre o surgimento dos exames como prática disciplinar na escola moderna, o caráter de exceção que os rituais de exame assumem na trajetória dos alunos que frequentaram a escola no século XIX no Brasil e a lenta definição do ritmo anual como característico da escola obrigatória. Em seguida, busco compreender como, nas primeiras décadas republicanas, a adoção do ensino seriado representou um lento e decisivo processo de mudança na cultura escolar, no qual a circulação de discursos especializados sobre a eficiência do ensino e dos padrões de normalidade no desempenho escolar das crianças teve efeito fortemente prescritivo das práticas e dos comportamentos. Discussões em relação à importância dos testes e às vantagens da organização de classes homogêneas engendraram a ampla circulação da crença de que a maioria dos indivíduos aprende da mesma maneira e nos mesmos ritmos. Por fim, defendo que a existência de estatísticas de educação - especialmente de matrícula, frequência e reprovação, especialmente —, sistemáticas e de melhor qualidade após 1931, é determinante para a percepção dos educadores e gestores públicos daquele período acerca do que passa a ser considerado como "distorções" do percurso escolar dos alunos, dando ensejo a um debate que acentuava as deficiências do alunado como causa do fenômeno e que propunha ações no âmbito da política educacional para tornar o ensino mais eficiente, mas não necessariamente mais adaptado às necessidades do alunado.

\section{PALAVRAS, NÚMEROS E PROBLEMAS: ALGUMAS CONSIDERAÇÕES TEÓRICO-METODOLÓGICAS}

É, em grande parte, em decorrência da existência de estatísticas de educação mais abrangentes e sistemáticas, nos anos 1930 e 1940, que determinados movimentos dos alunos pelas séries escolares podem ser percebidos, analisados e descritos como "distorções". Nesse sentido, os debates sobre a reprovação têm como condição de possibilidade a produção de estatísticas que permitem ver as características do movimento dos alunos na escola, avaliar o ritmo de aprendizagem e estabelecer, a 
partir disso, padrões de normalidade. A produção dos números depende, no entanto, do estabelecimento prévio de categorias que orientam a coleta dos dados, ou seja, depende da definição de determinadas situações sociais expressas em palavras. Fouquet (1995, p. 135-136) enfatiza que o trabalho do estatístico é contar o que foi previamente definido socialmente e que "os índices que ele publica são o resultado de inúmeras descrições da realidade frequentemente feitas sem ele, e das quais ele é apenas o contador". Essas definições e descrições são resultado de um processo histórico em que as palavras vão assumindo sentidos específicos de acordo com os usos sociais convencionados e, muitas vezes, não claramente expressos.

Assim, o trabalho aqui apresentado dialoga com os pressupostos da História dos Conceitos, conforme propõe Reinhart Koselleck. Segundo esse autor,

sem conceitos comuns não pode haver uma sociedade e, sobretudo, não pode haver unidade de ação política. Por outro lado, os conceitos fundamentam-se em sistemas político-sociais que são, de longe, mais complexos do que faz supor sua compreensão como comunidades linguísticas organizadas sob determinados conceitos-chave. (Koselleck, 2006, p. 98)

Destaca, ainda, a partir disso, que a História Social não pode, portanto, prescindir dos aportes da História dos Conceitos, na medida em que esta envida esforços no sentido de compreender "a partir de quando os conceitos passam a poder ser empregados de forma rigorosa como indicadores de transformações políticas e sociais de profundidade histórica” (Koselleck, 2006, p. 101). Assim, importa perscrutar o campo semântico dos conceitos buscando identificar o uso de termos nos âmbitos político e social pelos contemporâneos e pelas gerações precedentes, bem como perceber os embates pela definição dos termos, que visam a manter ou impor posições políticas e sociais.

Alheia a essas observações, a importância socialmente atribuída às estatísticas tem se assentado amplamente na crença compartilhada de que estas apresentariam uma descrição neutra e objetiva da realidade, assegurada pela universalidade dos números e pelo caráter inequívoco das palavras cuidadosamente escolhidas na composição das categorias. No entanto, as estatísticas estão longe de ter a neutralidade que frequentemente lhes é atribuída. Produzidas a partir de finalidades definidas por indivíduos determinados e restritas à possibilidade de apresentar apenas números constrangidos por categorias determinadas, as estatísticas mostram aspectos parciais da sociedade. As escolhas feitas - no arbítrio sobre quais assuntos podem e/ou devem ser contabilizados, na definição das categorias que servem de base à coleta dos dados primários, na seleção daquilo que deve compor as tabelas de divulgação dos resultados, nas comparações feitas etc. — não são automáticas nem evidentes e determinam a imagem obtida a partir dos procedimentos que caracterizam a produção desse tipo de conhecimento. Conforme alerta Besson (1995, p. 32), "é preciso compreender agora que não estamos diante de uma simples foto que poderíamos comparar com o que vemos". Ou seja, as estatísticas não "revelam" a realidade. Antes, a integram e participam na sua construção na medida em que 
conformam as maneiras pelas quais o real é percebido ${ }^{1}$. Tais escolhas, embora não sendo totalmente conscientes, vinculam-se às motivações que levaram à execução da investigação e correspondem a recortes necessários que resultam num ângulo, sempre, obrigatoriamente parcial.

A escolha por esta abordagem teórica define minha intenção em mostrar que a situação escolar que passa, no século XX, a ser descrita como problema de fluxo dos alunos pela escola é uma construção histórica que envolve, ao mesmo tempo, números e palavras. Nesse sentido, importa por um lado considerar, como se sugeriu acima, que as estatísticas são representações construídas a partir de condições determinadas e que acabam por colaborar para a construção de determinadas situações sociais, apesar de serem mencionadas como instrumento de mera descrição dessas situações. Por outro lado, interessa sublinhar que, tratando-se da análise histórica desses processos, não se pode deixar de considerar que as estatísticas são produzidas atreladas a palavras (categorias) cuja escolha e definição antecedem a coleta dos números. Tais palavras não guardam sentido inequívoco em seu próprio período de uso e, passado o tempo, vão sendo interpretadas de modos distintos.

Diante dessas considerações, é importante mencionar o sentido identificado, a partir da investigação do corpus documental, aos seguintes termos: reprovação, retenção e repetência. A reprovação corresponde, no período examinado, ao resultado nos exames ou nas avaliações finais que indica que o aluno não teve o desempenho mínimo estabelecido como desejável. A retenção é decorrência dessa reprovação, visto que determina, assumido o modelo de ensino seriado, a impossibilidade de o aluno seguir no fluxo normal de uma série à outra. Já a repetência aponta para o fenômeno da permanência na escola dos alunos retidos em determinada série, que vão se submeter a cursá-la novamente. A compreensão desses sentidos, como já se argumentou, não está dada para qualquer período histórico. Assim, é preciso considerar que o sentido atual que damos a esses termos constituiu-se progressivamente. Cabe lembrar que durante um longo período - e isso ocorre também nos dias atuais em determinados níveis ou modalidades de ensino - , diante da retenção, era frequente que o indivíduo abandonasse os estudos. Havia uma considerável naturalização desse abandono, permitindo supor que os resultados escolares fossem experimentados como sentença das (in)capacidades e (im)possibilidades dos indivíduos para seguir nos estudos. É apenas diante da obrigatoriedade escolar, atrelada ao convencimento social das vantagens da escolarização para toda a população, que a permanência na escola vai prevalecer, mesmo em face de resultados negativos, como a reprovação. É nesse contexto que cursar novamente uma mesma série passa a ser admissível e, cada vez mais, obrigatório, tornando quantitativamente expressiva a repetência.

Ou seja, esses movimentos não foram sempre assumidos como problema político-educacional. Essas ocorrências serão consideradas como distorções da trajetória dos estudantes apenas no século XX, quando predomina a expectativa de

1 Nesse sentido, importa assinalar que se assume aqui que as estatísticas exercem aquilo que Bourdieu (1998) chama de "efeito de teoria", já que, ao produzirem formas de inteligibilidade do mundo, criam as condições de existência daquilo que descrevem. 
que todos frequentem e concluam o ensino primário. Até os anos 1930, no Brasil, o debate girava basicamente em torno da questão do acesso das crianças à escola, evocando tanto a falta de vagas e prédios adequados para atender à população quanto o desinteresse das famílias em enviar os filhos à escola e mantê-los nela. A partir daquele momento, surge a preocupação com o fato de que as crianças que chegavam à escola não tinham garantia de êxito e permanência na instituição. Assim, passaram a ser recorrentes os debates acerca da necessidade de políticas que tornassem o ensino mais eficiente, que permitissem evitar que os alunos reprovassem de ano e interrompessem o percurso escolar. Nos anos 1940, a questão da repetência escolar vai aparecer mencionada na documentação, porém é apenas nos anos 1970 e 1980 que ganha destaque o debate que a descreve como um fenômeno indesejável a ser equacionado pelos gestores públicos.

Importa, nesse sentido, ressaltar que as situações sociais só são assumidas na agenda governamental como problema quando algumas condições estão presentes. Kingdon (1995, p. 109-110)2 em estudo no qual busca compreender como itens entram ou saem da agenda política e por que alguns itens e alternativas ganham destaque, enquanto outros são negligenciados, afirma que "situações passam a ser definidas como problemas quando começamos a acreditar que poderíamos fazer alguma coisa sobre elas. Problemas não são simplesmente situações ou eventos externos em si; existe também um elemento perceptual, interpretativo". Para que uma determinada situação seja assumida como problema é preciso que se apresente uma conjunção de elementos, tais como: o valor atribuído às observações, as comparações feitas e as categorias mobilizadas para descrever essa situação. Assim, uma mesma situação pode ser compreendida como problema, ou não, dependendo do valor que os sujeitos responsáveis pela definição da agenda dão a ela e se consideram que se trata de uma questão sobre a qual é possível agir. Também, as comparações entre situações podem fazer com que se delineie um problema. Kingdon (1995, p. 111) destaca que "se alguém não está atingindo ou obtendo o que outros conseguem atingir ou obter, e se se acredita em equidade, então a desvantagem relativa constitui um problema”. O autor menciona, ainda, que "as pessoas vão ver um problema de modo muito diferente se isso é apresentado em uma categoria em lugar de outra. Portanto, muitas das disputas sobre a definição dos problemas centram-se nas categorias que serão utilizadas e no modo como serão utilizadas"(Kingdon, 1995, p.111).

Kingdon enfatiza que os problemas não são autoevidentes e, portanto, é preciso compreender quais processos e elementos fazem com que determinada situação, que em outro momento seria desconsiderada, passe a receber a atenção dos governantes. Nesse ponto, as estatísticas têm um papel importante, assim como os debates travados a partir delas. Agências governamentais e não governamentais monitoram regularmente várias atividades e disso decorrem números e séries históricas de números que acabam sendo assumidos como indicadores de diversas situações. Vale ressaltar, conforme alerta o autor, que "estes indicadores ou estudos

2 Gostaria de agradecer a Líbia Aquino por me alertar acerca das potencialidades dos estudos de John Kingdon para compreensão da configuração dos problemas políticos. 
não determinam por eles mesmos se um problema existe ou não; tal determinação é uma questão de interpretação" (Kingdon, 1995, p. 91). No âmbito deste artigo, pretendo argumentar que a reprovação existe desde o surgimento da escolar moderna, mas só vai ser assumida como problema político-educacional no século XX. É na confluência dos debates que a assumem como questão merecedora de atenção e da existência e análise de estatísticas de educação que se podem identificar algumas das condições de possibilidade de que a reprovação se configure como problema político.

\section{OS EXAMES ESCOLARES E A DEFINIÇÃO DE UM TEMPO DE APRENDER}

Os exames existem desde o surgimento da escola moderna. Por exemplo, em 1599, quando é publicada a Ratio Studiorum, que apresenta detalhada orientação para o ensino nas escolas dos jesuítas, havia a previsão da realização regular de exames escritos em que os alunos apresentassem o resultado de suas aprendizagens (Saviani, 2007). Também na obra de Jan Amos Comenius, Didática Magna, publicada em 1657 e que traz fundamentos da pedagogia protestante do século XVII, estão propostos os exames, os exercícios e as sabatinas (Saviani, 2007). Foucault (1987, p. 166) destaca o caráter disciplinar dessa prática escolar e afirma que, na Modernidade, "a escola torna-se uma espécie de aparelho de exame ininterrupto que acompanha em todo o seu comprimento a operação do ensino". O autor ressalta, como exemplo, o regulamento dos Irmãos das Escolas Cristãs que previa a realização de provas de classificação dos estudantes constantemente. Tais considerações obrigam reconhecer que o exame, como prática sistemática escrita ou oral de comprovação das aprendizagens, está previsto desde, pelo menos, o século XVI.

No século XIX, no Brasil, não há na legislação imperial detalhamento sobre o desenvolvimento das atividades de ensino e avaliação. Assim, a realização dos exames vai ocorrer nas escolas de primeiras letras seguindo as regulamentações provinciais. Para o Rio Grande do Sul, por exemplo, segundo as Regulamentações de 1876 e 1927, os exames e os exercícios deveriam ser realizados anualmente em rituais coordenados pela inspetoria-geral (Hawat, 2015). Seriam definidos, com antecedência, data e horário e seria constituída uma comissão examinadora. Hawat (2015, p. 64) aponta que

os alunos considerados aptos para realizarem os exames eram interrogados individualmente, pelos examinadores, em todas as matérias, de acordo com o grau de ensino atingido $-1^{\circ}$ ou $2^{\circ}$. Após esta etapa de avaliação oral, que respeitaria o tempo que cada examinador considerasse "suficiente para formar seu juízo", o aluno realizava prova escrita, redigindo um trecho para avaliação de sua ortografia e caligrafia, e resolução de problemas de aritmética.

A partir dos desempenhos observados nessas avaliações, os alunos eram classificados em aprovados (simplesmente, plenamente e com distinção) ou reprovados.

Monica Yumi Jinzenji descreve, referindo-se a escolas para meninas em Minas Gerais, a realização de exames públicos na década de 1830. Segundo a autora, 
a publicação dos resultados dos exames em jornais era feita geralmente alguns dias após ocorrido o ato, e não apresentava muitas variações entre cada um deles, trazendo sempre a mesma ideia de que um cidadão presenciou o exame e em seguida relatava o ocorrido. Discorre sobre a quantidade de alunas presentes, os conteúdos examinados, o desempenho das alunas, dando destaque àquelas plenamente aprovadas ou adiantadas e, ao final, seguia o discurso feito pela professora na abertura do ato do exame. (Jinzenji, 2010, p. 183)

Ressalta, ainda, o baixo comparecimento das alunas nessas ocasiões por razões possivelmente variadas, entre as quais podem estar os constrangimentos de uma exposição pública na qual nem sempre tinham condições de apresentar bom aproveitamento dos estudos.

No entanto, seria um equívoco considerar que a experiência de participar dos exames fosse generalizada para a infância daquele período. Cabe lembrar que pouquíssimos indivíduos chegavam a frequentar a escola no século XIX. Mesmo entre aqueles que estiveram na escola por tempo suficiente para poderem ser submetidos a esse tipo de avaliação, os indícios apontam que a prática usual era mandar para exame apenas alunos cuja apreciação prévia dos docentes indicava que tinham condições de aprovação. Joseane El Hawat, analisando as atas dos exames realizados nas escolas públicas de Porto Alegre, entre 1873 e 1919, observa que são poucos os alunos submetidos ao ritual em comparação ao total de matriculados. Claramente, naquele contexto, não iam para exame todos os indivíduos que frequentavam a aula.

Poucos realizavam as provas públicas previstas pela legislação e a precariedade que caracteriza a produção das estatísticas escolares no período resulta na ausência de levantamento sistemático e publicação de números sobre as reprovações. Prevalecia uma compreensão social da exclusão escolar como algo natural e, efetivamente, em termos quantitativos essa era a regra. A análise de livros de matrícula de Porto Alegre permite observar que o tempo de permanência na escola até, pelo menos, a década de 1920 é muito curto ${ }^{3}$. A maior parte dos alunos, na documentação analisada, frequentava a escola por apenas 1 ou 2 anos, são raros os que frequentaram a mesma instituição por 3 e 4 anos e ainda mais raros os casos daqueles que permaneceram por mais de 5 anos.

Cabe destacar, ainda, que o período do ano em que as crianças podiam ser matriculadas na escola, ou seja, quando poderiam iniciar os estudos, é extremamente alargado. Para o Rio Grande do Sul, o decreto n. 89, de 1897, no art. 46, indicava que a inscrição das crianças poderia ser feita desde o início do ano até setembro. Em vários dos livros analisados, as matrículas iniciais aparecem concentradas nos primeiros meses do ano, de janeiro a abril. De qualquer modo, o que mais chama a atenção é o ingresso contínuo de alunos ao longo de praticamente o ano todo, quase sempre até a data limite estabelecia pela lei (outubro ou novembro). Isso implica

3 Foram analisados 22 livros de matrícula de escolas isoladas de Porto Alegre, localizados no Arquivo Histórico do Rio Grande do Sul, que cobrem o período de 1895 a 1919. Nesses documentos foram examinadas as características da entrada na instituição, como a idade dos sujeitos por exemplo, e das trajetórias dos alunos matriculados. 
considerar, como propõe Rita de Cássia Gallego, que os tempos da escola foram se definindo lentamente. Analisando a documentação de São Paulo, essa autora ressalta a historicidade desses aspectos ao lembrar que

o tempo escolar, como um dos tempos sociais, também é diverso e plural. Consiste em um sistema social de referências temporais a partir do qual se definem, organizam e regulam o funcionamento, os ritmos, a coordenação e a sincronização das interações no interior da escola; assim, é fruto de uma construção cultural e pedagógica. (Gallego, 2003, p. 18)

No que se refere aos exames e à reprovação, convém sublinhar que a própria noção do ano-calendário como tempo limite para a verificação das aprendizagens e definição de resultados, como aprovação e reprovação, é algo que só vai se fixar efetivamente no século XX.

Também as idades de aprender foram sendo estabelecidas nesse processo. Maria Cristina Gouveia destaca que, no Brasil, as leis de obrigatoriedade escolar estabeleceram a faixa etária dos alunos correspondendo, aproximadamente, ao que Rousseau indicava como o período de realização das aprendizagens, ou seja, entre 7 e 12 anos. Segundo a autora, no caso brasileiro,

o século 19 incorporou os discursos pedagógicos defensores da educabilidade da infância, do papel civilizatório da educação e, no interior dessa reflexão, da definição de um período ideal para a aquisição da instrução elementar. Nos oitocentos, essa cada vez mais foi compreendida como devendo se realizar nos espaços escolares. Era à criança no período da meninice, compreendida entre os 7 e 14 anos, que foram dirigidos os projetos de instrução pública. (Gouveia, 2004, p. 275)

Em concordância com a interpretação dessa autora, como de outros, os resultados da pesquisa empírica em livros de matrícula, na qual se ancora o estudo aqui apresentado, têm evidenciado que o processo de definição da infância pela condição de aluno foi lento. A legislação do Rio Grande do Sul, em 1897, por exemplo, indicava que "só serão admittidas á matrícula nas escolas públicas as crianças de 7 a 13 annos de idade" (decreto n. 89, art. 39). A análise dos livros de matrícula, contudo, permite ver a presença eventual de crianças de 4 a 6 anos e indica a frequência de alguns indivíduos com idade acima da mencionada na legislação. Isso permite argumentar que a normalização dos tempos de aprender e a definição da progressão anual na escola, embora estivessem previstas desde antes, não predominam nas práticas escolares até, pelo menos, os anos 1920 . Ora, assumir a reprovação e a repetência como distorções do fluxo dos alunos pelas séries escolares pressupõe a padronização desses tempos na legislação e no discurso que prescreve as práticas pedagógicas. Mas também implica em uma mudança da cultura escolar, sendo que esta não é uma decorrência imediata e automática daquela padronização. Assim, é com a ampla adesão do pensamento pedagógico e da prática docente à ideia de homogeneidade e padronização, bem como com a efetiva ampliação das vagas na escola obrigatória, que passa a ser possível ver na exclusão dos alunos que não aprendem um problema educacional. 


\section{SERIAÇÃO E HOMOGENEIDADE DAS CLASSES}

A organização seriada no ensino primário vai, ao longo dos séculos XIX e $\mathrm{XX}$, em todo o Ocidente, ser constituída como denotativa da racionalidade pedagógica considerada coerente, durável e adequada para a universalização do ensino (Souza, 2006). "Baseada na classificação homogênea dos alunos, na existência de várias salas de aula e vários professores" (Souza, 1998, p. 15), a escola seriada vai implicar, entre outras coisas, no desenvolvimento de uma arquitetura apropriada, na criação de mobiliário e material didático específicos e em uma nova compreensão dos tempos e dos ritmos de aprendizagem.

No Brasil, a primeira iniciativa nesse sentido acontece em São Paulo, no bojo das proposições encabeçadas pela elite republicana que pretendia organizar a sociedade em consonância com o novo regime. Em 1893, são criados os grupos escolares paulistas nos quais o ensino era organizado em séries, cada qual disposta em sua sala de aula regida por um mesmo professor. Isso implica destacar que a escola seriada paulista pressupunha o ensino simultâneo, em que os conteúdos eram ensinados a todos os alunos da mesma maneira e ao mesmo tempo.

A adoção do ensino simultâneo e da seriação pautava-se na compreensão acerca da possibilidade e necessidade da organização de classes homogêneas. Considerava-se que, para que a escola fosse eficiente, capaz de ensinar nos tempos estabelecidos pelos programas oficiais, era preciso aperfeiçoar os critérios de composição das classes de modo que frequentassem uma mesma série aqueles alunos cujos desempenhos de aprendizagem e domínio dos conteúdos fossem equivalentes. A composição de tais classes se assentou basicamente em dois recursos. O primeiro deles centrou a atenção na avaliação prévia das capacidades de cada criança, antes mesmo do início da escolarização, recorrendo-se, para isso, a testes psicológicos, de escolaridade, de desenvolvimento. $\mathrm{O}$ segundo recurso era a avaliação propriamente escolar, que repousava, sobretudo, no domínio do programa ensinado, conduzindo à aprovação ou à reprovação ao final do ano letivo. Assim, o estudante que não comprovasse domínio suficiente dos conteúdos ensinados em uma determinada série ficava impedido de seguir para a série subsequente, tendo de refazer a série em que foi reprovado. Ou seja, repetia o ano, tornando-se repetente. Nessa configuração, a reprovação, a retenção e a repetência são compreendidas como necessárias para o adequado e eficiente funcionamento da escola.

Se funcionasse conforme o previsto, esse modelo permitiria que a cada série escolar correspondesse uma faixa de idade do alunado. Logo, idealmente, as crianças iniciariam a escolarização aos 7 anos na $1^{\mathrm{a}}$ série, estariam aos 8 anos na $2^{\mathrm{a}}$ série e assim por diante. Porém, efetivamente, a regularidade nesse fluxo não se confirmou no cotidiano das instituições e já nas primeiras décadas do século XX são frequentes as discussões acerca das distorções que impediam o bom funcionamento do modelo. Diante disso, o que se colocou em questão não foi a adequação do pressuposto que sustentava o modelo seriado, e sim as incapacidades e limitações dos alunos. Seguiram-se amplos debates e numerosos estudos que pretendiam identificar as crianças "anormais", a fim de evitar que elas atrapalhassem o bom funcionamento da escola. Baseada nessa compreensão, a melhoria do ensino pressupunha, portanto, 
o desenvolvimento de testes que permitissem identificar e classificar os estudantes lentos ou incapazes.

Os testes para seleção e classificação do alunado foram, então, ensinados e amplamente aconselhados aos docentes como prática capaz de auxiliar na melhoria da qualidade do ensino primário. Nos manuais de psicologia destinados aos professores, que circularam no início do século XX, com recorrência

recomendava-se o recurso aos testes de inteligência, especialmente aqueles formulados por Binet, que permitiam identificar as crianças retardadas e estabelecer o nível mental de cada aluno, tendo em vista encaminhá-lo para a modalidade de ensino mais adequada às suas necessidades individuais. (Lima e Viviani, 2015, p. 103)

Alfred Binet foi um dos mais importantes investigadores da psicologia experimental na Europa e, desde o final do século XIX, empenhou-se no desenvolvimento de procedimentos supostamente capazes de medir as funções mentais (Monarcha, 2009). Em 1904, Binet foi designado pelo Ministério da Instrução Pública na França a integrar uma comissão cuja atribuição era diagnosticar o nível mental dos estudantes, "para posterior criação de classes especiais e aplicação de programas de ensino adequados aos níveis de inteligência apurados" (Monarcha, 2009 , p. 186). Interessava ao governo francês, especialmente, identificar os alunos com baixa capacidade intelectual, a fim de retirá-los das escolas regulares, pretendendo garantir, assim, um rendimento pedagógico mais eficiente. Nesse sentido, Claparède, entusiasta da proposta, afirmava:

Estamos na época em que a questão das crianças anormais começa preocupar os espíritos na França. Ao passo que na Alemanha, a Bélgica, a Suíça, possuíam há muito tempo um ensino especial para esta categoria de crianças, nada ainda tinha sido previsto para elas, na organização escolar francesa. (apud Monarcha, 2009, p. 186)

Os estudos realizados por Binet foram lidos com interesse pela elite brasileira, que se autoinstituiu na função de organizar a nação por via da escolarização. De viés fortemente liberal, esses sujeitos se empenharam em "evolver as práticas biométricas e propor uma educação condizente com as habilidades inatas, modo como se pensava resolver o dilema igualdade jurídica e diferença biológica"(Monarcha, 2009, p. 208).

Dos testes psicológicos propostos para a escola brasileira nesse período, interessa destacar os "Testes $\mathrm{ABC}$ ". Desenvolvidos por Lourenço Filho, na ocasião ocupando a cadeira de Pedagogia e Psicologia da Escola Normal da Praça da República, em São Paulo, e fortemente baseados nos estudos de Binet, os "Testes ABC", por intermédio de um conjunto de provas para avaliação da coordenação motora, memória, atenção etc., buscavam identificar os níveis de maturidade dos educandos para o aprendizado da leitura e da escrita. No livro Introdução ao estudo da Escola Nova, de 1930, Lourenço Filho (apud Monarcha, 2009, p. 221) afirmava:

4 Cabe ressaltar que apenas nos anos 1930 os “Testes ABC" vão ser debatidos nos meios educacionais e usados em escolas. 
De tentativa em tentativa, a psicologia experimental logrou obter meios práticos para as investigações necessárias à classificação dos indivíduos, hoje possível sem longo ou penoso trabalho, por meios objetivos relativamente simples. Esses meios são os testes psicológicos, pequenas provas, sob condições bem definidas, e cujos valores significativos só são fixados depois de investigações bioestatísticas.

Por eles, não só se chega à organização racional de classes homogêneas, ao ensino seletivo e diferenciado (ou "sob medida", como lhe chamou Claparède), mas ainda à classificação científica dos anormais de inteligência, à organização de classes ou escolas para os supernormais, à orientação e seleção profissional, à discriminação dos temperamentos e aptidões especiais.

Estavam aí, portanto, claramente expressos os princípios da racionalidade pedagógica. Assim, seria possível identificar as crianças retardadas, para quem o ensino comum seria improdutivo, e organizar classes seletivas na $1^{\text {a }}$ série primária, cada qual sendo educado de acordo com seu ritmo. Dessa maneira, pensava-se ser possível organizar classes homogêneas nas quais o ensino simultâneo seria não apenas possível como eficiente.

Em face de preocupações semelhantes, entre 1933 e 1935, a Divisão de Obrigatoriedade Escolar e Estatística, do Distrito Federal, intentou a classificação homogênea dos alunos. Paulilo (2012, p. 42) enfatiza que "a formação das classes nesses anos foi uma possibilidade técnica não apenas de organizar a escola, mas de fazê-la render, de otimizar seus processos e assegurar as aprendizagens”. A composição dessas classes recorreu aos testes em voga no período. Nesse processo, segundo o autor,

não só agregou provas estandardizadas ao domínio das observações escolares, considerou ainda as eventualidades do comportamento para distinguir uma classe de alunos da outra. $\mathrm{O}$ grau de atenção dedicada às configurações objetivas da sala de aula situou mais que a criança, o seu rendimento, a sua aptidão, as suas manifestações expressivas, o seu caráter, na conta das políticas públicas de educação. (Paulilo, 2012, p. 42)

A racionalidade classificatória pautava a convicção de que quanto mais precisos fossem os procedimentos para distribuição homogênea dos alunos, melhores seriam os resultados em termos de aprendizagem. Em 1936, foi publicado, pela Secretaria de Educação e Saúde Pública de São Paulo, um boletim intitulado As reprovações na escola primária, que apresentava estudo sobre a questão produzido a pedido de Almeida Júnior, então secretário ${ }^{5}$. Luiz Gonzaga Fleury, autor desse estudo, sustentava que uma das causas de reprovação eram as "classes heterogêneas, quer quanto ao grau de aprendizagem dos alunos, quer quanto ao seu índice mental”(São Paulo, 1936, p. 17).

5 Foram analisados 18 números dos Boletins publicados pela Diretoria de Ensino da Secretaria da Educação e da Saúde Pública de São Paulo, entre 1936 e 1938, durante a gestão de A. Almeida Júnior. 
Ressaltava, ainda, que essa causa não poderia ser evitada nas escolas isoladas - onde eram, aliás, segundo ele, mais elevadas as taxas de reprovação - , ou mesmo nos grupos escolares pequenos, mas the parecia inegável a necessidade, nas demais escolas, de melhores e mais abrangentes processos de seleção dos estudantes e organização das classes. Em outro boletim publicado pela mesma Secretaria, Noemy Silveira Rudolfer, do Laboratório de Psicologia Aplicada do Instituto de Educação, informava que numa classe cujo agrupamento tenha se dado sem nenhum critério, há a probabilidade de estarem $16 \%$ de alunos fortes, $16 \%$ de fracos e $68 \%$ de médios. Daí concluía que, desse modo, o ensino seria sempre inadequado a uma parte significativa de alunos. Assim, justificava uma sequência detalhada de procedimentos a serem empregados nas escolas, como a distribuição dos estudantes em classes fortes, médias e fracas, o regime de dupla promoção no ano letivo, a organização de classes especiais para os casos mais acentuados e o emprego dos Testes ABC, Dearborn e Ballard, além da consideração do rendimento escolar do ano anterior.

É preciso ressaltar que a ênfase na homogeneidade das classes nas proposições do ensino seriado no país significou, conforme destaca Souza (2006), o estabelecimento de uma contradição: buscava-se maior eficiência da instituição, de modo a permitir democratizar a escolarização ao mesmo tempo em que se reforçava a seletividade e exclusão escolar. Segundo a autora,

no plano pedagógico, o estabelecimento das divisões nas escolas possibilitou um rendimento melhor da instituição escolar, porém a escola tornou-se mais seletiva porque o agrupamento dos alunos em classes homogêneas supunha o favorecimento dos melhores em detrimento dos mais "fracos". Além disso, a classificação em cursos gerou aperfeiçoamento dos exames e criou a noção de repetência, que viria a se constituir em um dos maiores problemas do ensino primário em todos os tempos. (Souza, 2006, p. 45, grifo do original)

Percebe-se, portanto, já nas primeiras décadas do século XX, que a repetência surge como noção e a reprovação começa a aparecer na documentação oficial como questão a inspirar atenção. Porém, nenhuma delas tinha adquirido ainda, naquele momento, feição de problema para a gestão da educação pública brasileira. É preciso considerar que os discursos especializados que apoiaram as ações de formação docente e os discursos oficiais que buscavam prescrever as práticas escolares legalmente autorizadas, durante as primeiras décadas republicanas, fazem ver a existência dessas questões. Mas, em termos quantitativos, o atendimento escolar ainda se mantinha bastante restrito. Por um lado, importa destacar que até os anos 1930 uma parcela muito reduzida da população chegava à escola, qualquer que ela fosse, e nela ficava pouco tempo. Por outro lado, mesmo com o aumento contínuo do acesso à educação ao longo de todo o século XX, demorou mais do que tem sido suposto para que a maioria dos alunos estivesse frequentando escolas seriadas, regidas por professores que tivessem recebido formação docente de acordo com os discursos pedagógicos modernos (que ensinavam a lecionar de modo simultâneo em classes homogêneas, por exemplo), organizadas de acordo com as prescrições já referidas. Esses dois elementos permitem compreender por que, apesar da circulação de discursos es- 
pecializados e oficiais acerca da seletividade escolar desde antes, a reprovação e a repetência não aparecem efetivamente como problema político-educacional antes dos anos 1930. Acrescente-se a isso a falta de uma estatística bem organizada que fosse capaz de contabilizar para todo o país o movimento escolar, registrando alunos aprovados e reprovados, os repetentes, os evadidos. Ou seja, era pequeno ainda o contingente que chegava a ser matriculado, nem sempre esses indivíduos estavam submetidos efetivamente aos tempos e ritmos impostos pela legislação e pela moderna pedagogia, e a capacidade de o Estado conhecer quantitativamente esses fenômenos era ainda insuficiente.

\section{A ESTATÍSTICA ESCOLAR E A VISIBILIDADE DA REPROVAÇÃO}

A produção das estatísticas escolares vai ser aperfeiçoada ao longo da década de 1930, ampliando-se as categorias coletadas e avançando em termos de técnica ${ }^{6}$. Em 1930, é criado o Ministério da Educação e não demora para que seja proposto na estrutura do órgão um setor especificamente destinado à produção das estatísticas de educação ${ }^{7}$. Em 1937, com a criação do Instituto Nacional de Estudos e Pesquisas Educacionais Anísio Teixeira (INEP), tem-se novo impulso nesse sentido, visto que uma das funções do novo órgão era a realização de estudos sobre a situação educacional do país, compreendendo entre esses a organização de estatísticas mais confiáveis e completas.

Em 1931, tem-se a assinatura do Convênio Interadministrativo das Estatísticas Educacionais e Conexas, iniciativa inédita no país com vistas à articulação de esforços entre os entes federados na realização desses levantamentos. Tal convênio vai efetivamente permitir realizar levantamentos mais sistemáticos e regulares abrangendo todo o território nacional. Também vai tencionar as unidades federadas no sentido de buscarem esses dados, preencherem os formulários, seguirem as categorias padronizadas. Embora esse processo seja cheio de falhas e lacunas, frequentemente apontadas nos relatórios pelos responsáveis pelas compilações de dados, permitiu alguma organicidade na produção estatística e resultou numa quantidade expressiva de informações sobre as matrículas. Esses números vão viabilizar, ao longo da década seguinte, a elaboração de interpretações e análises do movimento escolar, da ampliação das matrículas, das irregularidades de fluxo.

Ao lado da efetiva ampliação do acesso à escola observado após 1930, a possibilidade de contar com maior quantidade de dados estatísticos reputados como de boa qualidade permite ver a reprovação, a repetência e a evasão escolar

6 Esse é um processo pelo qual passam as estatísticas brasileiras em geral no mesmo período. Tem-se, por exemplo, a criação do IBGE em 1937, a concordância entre os especialistas sobre a maior qualidade dos dados do censo de 1940, a crescente matematização dos procedimentos demográficos nas décadas seguintes. Para maiores detalhes acerca da organização das estatísticas no Brasil ver Senra (2006; 2014).

7 Em 1931, com a criação do Ministério da Educação, foi instituída a Diretoria Geral de Informações, Estatística e Divulgação. Em 1939, passa a se chamar Serviço de Estatística de Educação e Saúde (SEES). 
como fenômenos estatisticamente expressivos. A própria publicação sistemática dos números, por si só, permitia ver as distorções de fluxo, o que talvez já existisse há muito tempo, mas sem a visibilidade permitida pelos números. $\mathrm{O}$ aumento dos números absolutos de matrícula também vai assumir, pela simples grandeza das cifras, uma feição espantosa.

Em 1936, no boletim As reprovaçôes na escola primária, já mencionado, a análise do movimento de reprovação nas escolas primárias paulistas era feita recorrendo-se às estatísticas escolares disponíveis no período. $\mathrm{O}$ estudo concentrava-se em dados de 17 municípios da região da capital do estado. Nessa região, em 1935, das 116.060 crianças submetidas a exame, 48.824 haviam sido reprovadas, configurando um índice de $42 \%$ de reprovação. Nas análises presentes no boletim fica evidente que a consideração de Almeida Júnior acerca das estatísticas não é ingênua. Nesse sentido, o autor afirma que "as reprovações são dados numericos exactos; mas os critérios que as determinam, bem o sabemos, mudam de escola para escola" (São Paulo, 1936, p. 3). Argumenta que era necessário compreender que "há autoridades 'baixistas', que se contentam com pouco, também as há 'altistas', dispostas a apertar o crivo das aprovações” (São Paulo, 1936, p. 3). Expressa, assim, a possibilidade de assumir os números apenas parcialmente, em função de variantes como a apontada acima. No que se refere às reprovações, por exemplo, não deixa de concordar que indiquem um problema da escola paulista, mas sua ênfase argumentativa não recai nisso quando, a propósito, afirma que "promover é importante, porque significa efficiencia do ensino informativo, - mas não esgota das funções da escola" (São Paulo, 1936, p. 3).

Nos boletins do INEP, publicados entre 1939 e 1944 pelo governo federal ${ }^{8}$, também tem destaque a discussão sobre o fluxo dos alunos pelo ensino primário. Nessas publicações, o eixo primordial das análises é a matrícula de crianças no ensino primário. O mais comum é a comparação dos totais de matrículas em momentos diversos. A partir disso, calculam-se os índices de crescimento de matrícula em cada estado do país, comparando-os, então, à média nacional. Nos boletins, a discussão sobre o rendimento da escola remete quase sempre à capacidade de matricular contingente expressivo da população escolar. Raramente aparece a questão das aprovações como merecedora de atenção. Estão, no entanto, presentes em alguns momentos. No Boletim n. 19, por exemplo, figuram dados sobre crescimento do número de instituições de ensino primário, de docentes diplomados, de matrícula

8 No que se refere à documentação em âmbito federal, foram analisadas, na pesquisa que dá sustentação à argumentação aqui apresentada, aquelas elaboradas, sobretudo, no Serviço de Estatística de Educação e Saúde (SEES), sob a coordenação de Teixeira de Freitas, e no Instituto Nacional de Estudos Pedagógicos (INEP), organizadas por Lourenço Filho. Ambos os órgãos eram subordinados ao Ministério da Educação. No primeiro caso, foi analisada a série "O ensino no Brasil", publicada entre 1939 e 1946. No segundo caso, foram analisados os boletins do INEP entre 1939 e 1944. Em 1944, o INEP cria a Revista Brasileira de Estudos Pedagógicos, cujos artigos também foram considerados nesta análise. Outro periódico investigado foi a Revista Brasileira de Estatística, publicada desde 1940. Além desses documentos, foram examinados alguns livros de autores que participavam das discussões acerca das estatísticas de educação no período. 
geral, além de informações sobre aprovação e conclusões de curso: "Deve-se notar que o movimento de aprovações, em geral, e o de conclusões de curso, especialmente do ensino fundamental comum, acusou, no mesmo período, crescimento mais acentuado que o da matrícula" (Ministério da Educação e Saúde, 1942,p. 15). A partir disso, conclui-se: "Não só maior número de alunos tiveram oportunidade, portanto, de frequentar escolas, mas também maior percentagem de alunos lograram o benefício de aprovação e de cursos completos" (Ministério da Educação e Saúde, 1942, p. 15).

No boletim intitulado O ensino no Brasil no quinquênio 1932-1936, publicado em 1939, argumenta-se que, para que se possam apreciar o "trabalho real" e a "eficiência do ensino", seria preciso examinar o movimento de matrícula, as promoções e as conclusões de curso. A observação faz supor que o rendimento do ensino estaria assentado em dois elementos inter-relacionados: o primeiro deles era a frequência dos alunos às aulas, sem o que, aliás, acreditava-se serem pouco prováveis os progressos do segundo fator, a saber, o resultado dos exames de fim de ano. Lourenço Filho, responsável pela publicação dos boletins, enfatiza, nesse sentido, que "o número de unidades escolares indica a oferta do ensino. A matrícula geral, a sua procura. Mas a verdadeira medida do resultado do trabalho escolar só nos será fornecida pelas taxas de promoção e de conclusão de curso" (Ministério da Educação e Saúde, 1939, p. 33, grifos do original). Na ocasião, para o ensino primário geral, os dados de aprovação apresentados eram os seguintes (Quadro 1).

Nota-se que menos da metade dos matriculados obtinha aprovação no período.

No boletim Situação geral do ensino primário, publicado em 1941, aparece um item, "Aspectos gerais do rendimento do ensino", em que são apresentados dados de matrícula geral, porcentagem de aprovações sobre o total de matrícula e as conclusões de curso. No que se refere a esses dados, tem-se a seguinte análise: "As taxas gerais de aprovação, calculadas sôbre a matrícula efetiva, ou de alunos remanescentes no fim do ano, veem exprimir [...] o rendimento real do ensino ministrado, permitindo julgar da deficiência global do aparelho escolar existente" (Ministério da Educação e Saúde, 1941, p. 40, grifos meus). De acordo com esse documento, em 1937, a aprovação foi de 52,1\%. Apesar da menção, que indica que tais números são percebidos como problema na escola primária brasileira, a discussão mais destacada, no que se refere ao rendimento, aparece em torno do que ali se denomina "êxodo", “evasão" ou "deserção" de alunos. Em 1937, dos 2.702.383 indivíduos matriculados no ensino primário, 417.479 teriam deixado a escola precocemente $(15,45 \%)$.

Merece destaque, nesse sentido, um debate travado entre Teixeira de Freitas e Lourenço Filho, nos anos 1940, que evidencia a importância atribuída à questão, pelo

Quadro 1 - Dados de aprovação para o ensino primário geral.

\begin{tabular}{|l|c|c|c|}
\hline Anos & Matrícula & Aprovações & Taxa \\
\hline 1932 & 2.071 .437 & 831.223 & $40 \%$ \\
\hline 1936 & 2.750 .014 & 1.153 .212 & $42 \%$ \\
\hline
\end{tabular}

Fonte: Ministério da Educação e Saúde (1939, p. 33). 
próprio empenho de ambos na argumentação, e sinaliza interpretações em disputa. Em 1940, aparece publicado na Revista Brasileira de Estatística o artigo "Dispersão demográfica e escolaridade", de Teixeira de Freitas (1940a). Esse mesmo estudo foi aprofundado e desenvolvido em certos pontos para ser apresentado em sessão pública da Sociedade Brasileira de Estatística, em novembro de 1940, sob o título de "A evasão escolar no ensino primário brasileiro" (Teixeira de Freitas, 1940b). A mesma revista vai publicar, em 1941, um artigo em que Lourenço Filho apresenta suas discordâncias quanto às análises apresentadas naquele estudo. Segue-se, por fim, em resposta às críticas feitas por Lourenço Filho, um último artigo de Teixeira de Freitas (1941) — "Ainda sobre a evasão escolar no ensino primário brasileiro".

Vários aspectos são debatidos pelos autores nesses artigos. Uma das significativas divergências entre os autores dizia respeito exatamente aos índices de repetência. Cabe reafirmar que esse problema ainda não aparecia no debate educacional com a gravidade com que se convencionou mencioná-lo na segunda metade do século XX. É, antes, considerado um elemento natural e inevitável no movimento escolar - assim como a evasão, até certo ponto. Teixeira de Freitas aponta a evidência de uma acentuada melhoria de rendimento da $2^{\mathrm{a}}$ série em relação à $1^{\mathrm{a}}$ e também da $3^{\mathrm{a}}$ comparada à $2^{\mathrm{a}}$, embora esta última diferença seja mais fraca. $\mathrm{O}$ autor ressalta que

essa melhoria, no entanto, - cumpre assinalar - não deve ser interpretada como elevação rápida do nível mental do discipulado, nem como eficiência maior do ensino nas séries superiores. É óbvio que ela decorre da progressiva seletividade com que se constituem as séries ulteriores à primeira, em virtude do próprio êxodo verificado, que vai naturalmente eliminando do corpo discente os menos aptos ou menos aplicados. (Teixeira de Freitas, 1940a, p. 504, grifos meus)

Decorre disso a incoerência, apontada por Lourenço Filho, em se utilizar, no estudo estatístico apresentado, um índice de evasão igual para cada uma das diferentes séries do ensino primário, bem como a opção por desconsiderar a ocorrência de repetição da mesma série por mais de uma vez. Ele critica, por não ser o que se observava de fato, o "critério adotado, que foi o de computar a repetência por uma só vez no $1 .^{\circ}$ ano, por duas no $2 .^{\circ}$, e por três no 3. ${ }^{\circ}$ (Lourenço Filho, 1941, p. 543). Continua sua argumentação ressaltando a evidência de que "as mais elevadas taxas de repetência simples, ou de sua incidência múltipla, apresentam-se justamente nas primeiras séries ou graus do curso. E estas, como é óbvio, conteem os maiores efetivos" (Lourenço Filho, 1941, p. 543) e completa afirmando que "como se pode ver em publicações oficiais, a repetência por três, quatro e até cinco vêzes, no 1. ${ }^{\circ}$ ano escolar, existe mesmo nos sistemas escolares das cidades, como o Distrito Federal" (Lourenço Filho, 1941, p. 543).

Na resposta que dá a essa crítica, Teixeira de Freitas (1941, p.572, grifos do original) afirma que Lourenço Filho teria observado mal a tabela apresentada no estudo:

Mas releia o nosso caro professor Lourenço Filho, a tabela em causa, reparando no sentido das abreviaturas. E então verá que não se encontra na tabela o que supôs, senão exatamente "a abstração do caso particular da repetência múltipla 
da mesma série". Vejamos, por exemplo, o movimento da 3. a série em 1936. As três parcelas que lá se encontram aludem, certo, a repetentes; mas não são repetentes da série (a 3.a) mais de uma vez, e sim novos ou repetentes da 3. a série pela primeira vez, mas que foram anteriormente repetentes — de uma, de outra ou de ambas as séries precedentes (a 1. ${ }^{\mathrm{a}}$ e a $2 .^{\mathrm{a}}$ ), nunca, entretanto, mais de uma vez em cada uma delas - talqualmente o pressuposto estabelecido.

Esclarecido que o que parecia se referir a repetências múltiplas da mesma série não o era, caberia ainda questionar por que o autor desconsiderou esse fenômeno em sua análise. Segundo ele, como não há estudos nem dados que correspondam a todo o país no que se refere à ocorrência de repetências múltiplas, optou-se por utilizar um recurso técnico, qual seja: fazer uma substituição, com erro desprezível, considerando-se todos os repetentes como simples. Teixeira de Freitas (1941, p.578) argumenta que "estatisticamente, nos é lícito considerar tais efetivos senão equivalentes do modo rigoroso, ao menos tão minimamente discrepantes que se possam na prática considerar iguais". Para proceder desse modo, o autor alega que, para o objetivo do estudo - saber o momento em que cada geração teria se desligado da escola - esse artifício seria satisfatório.

Teixeira de Freitas considerava que a repetência múltipla não tinha tanta significação, a ponto de ser preciso considerá-la. Vale lembrar que as conclusões que esse autor tira de seu estudo estatístico apontam primordialmente para o problema da evasão. Assim, o que ele quer ressaltar é que as crianças saem da escola antes de completar a escolaridade por ele considerada o mínimo admissível naquele período. Nesse sentido, é razoável que ele dê pouca importância à multirrepetência, visto que, seguindo o seu raciocínio, é de se convir que, em vez de se manter na escola refazendo a mesma série várias vezes, a maior parte das crianças reprovadas, com maior ou menor resistência, dela acabava se retirando sem concluir o curso. Lourenço Filho, contudo, não compartilha dessa mesma opinião. Segundo ele, para uma análise completa do fenômeno da evasão, "seriam necessários os índices de dupla repetição de ano, especialmente importante na $1^{a}$ série escolar, em que a variedade de critérios de classificação de alunos é tão grande de um para outro sistema de ensino" (Ministério da Educação e Saúde, 1941, p. 38).

É interessante, ainda, observar que Lourenço Filho (1941) defende a necessidade de considerar que as reprovações no $1^{\circ}$ ano nem sempre têm a significação pedagógica de uma reprovação de fato. Isso porque, segundo ele, "na verdade, não temos em nossas escolas uma primeira série a realizar-se, normalmente, em um ano de estudos" (p. 544). Ou seja, em algumas regiões, em uma mesma instituição, tinha-se um primeiro ano "atrasado" e outro "adiantado". Rocha (2013) identifica essa situação ao analisar livros de matrícula do grupo escolar de Sabará, em Minas Gerais, entre 1907 e 1916. Segundo a autora, a prática corrente naquela instituição era dividir o programa do $1^{\circ}$ ano em duas partes, desenvolvidas, cada qual, durante um ano letivo. Até 1912, aparecem na documentação as denominações "10 ano do $1^{\circ}$ semestre" (referindo-se aos conteúdos previstos para o primeiro semestre do $1^{\circ}$ ano) e " $1^{\circ}$ ano do $2^{\circ}$ semestre". A partir de 2013, surgem, naquela documentação, as expressões " $11^{\circ}$ ano atrasado" e " $1{ }^{\circ}$ ano adiantado". Nessas circunstâncias, 
“a retenção está muito mais relacionada com as práticas escolares do grupo, na tentativa de conseguir cumprir o conteúdo previsto pelo programa” (Rocha, 2013, p. 10). A autora ressalta que as crianças menores - do $1^{\circ}$ ano do $1^{\circ}$ semestre ou $1^{\circ}$ ano atrasado - sequer eram submetidas a exame, sobretudo as mais novas - de 6 e 7 anos de idade, por não serem consideradas ainda preparadas para avaliação. É nesse sentido que Lourenço Filho (1941, p. 544) defendia que se deve considerar que "para os alunos, para os pais, e para o efeito da apreciação do trabalho dos próprios professores, muitas vêzes, a passagem dos alunos de um $1^{\circ}$ ano $\mathrm{A}$, para um $1^{\circ}$ ano B, ou do atrasado para o adiantado; significa promoção”.

É possível notar, na análise aqui apresentada, que o que dá ensejo ao debate é, efetivamente, a existência de estatísticas sobre o movimento dos alunos pela escola. Tais números não foram produzidos pretendendo-se mensurar o fenômeno da reprovação, da repetência ou, até mesmo, da evasão. A intenção era acompanhar, sobretudo, a ampliação das matrículas e o alcance do ensino primário brasileiro. No entanto, a existência dessas informações vai dar visibilidade a questões inicialmente imprevistas, como é o caso da repetência e da evasão. Nesse sentido, os documentos analisados são inaugurais ${ }^{9}$ de um debate importante, que não encontrava, até então, condições de possibilidade suficientes para ser enunciado. Mesmo que a reprovação, a repetência e a evasão tenham se configurado como movimentos possíveis dos alunos pela escola antes de 1930 - visto que se atrelam ao surgimento da escola moderna e, em seguida, à adoção do modelo seriado - é com as estatísticas que se têm elementos que tornam visível e expressiva sua dimensão quantitativa, habilitando-as, em alguma medida, a serem assumidas como problemas na agenda política, conforme nos sugere a análise de Kingdon (1995).

\section{CONSIDERAÇÕES FINAIS}

Neste artigo, pretendeu-se argumentar que, embora os exames escolares e a reprovação dos alunos existissem desde a instalação da escola moderna no Brasil, ainda no período colonial, é apenas a partir dos anos 1930 que os maus resultados escolares entram na agenda política como problema da educação nacional. Assumir a existência dos exames escolares não significa dizer que todos os estudantes eram submetidos a esses rituais. No século XIX, apenas aqueles considerados aptos por professores e inspetores do ensino, a partir de critérios pouco explícitos, é que faziam os exames. Nessas ocasiões, podiam ser reprovados ou aprovados - simplesmente, plenamente ou com distinção. Conforme se consolida a escola obrigatória e se estabelece que as séries anuais devem organizar os ritmos e os tempos de aprender, durante um lento processo que só se define na República, assiste-se a um decisivo processo de mudança na cultura escolar. Nesse sentido, a circulação de discursos especializados acerca da eficiência do ensino e dos padrões de normalidade no

9 Embora possam não ser os únicos, visto que a pesquisa restringiu-se apenas a Rio Grande do Sul, São Paulo, Minas Gerais, Distrito Federal e à documentação publicada pela administração central - MEC, INEP, SEES e IBGE. 
desempenho escolar das crianças acaba por assumir uma feição fortemente prescritiva das práticas e dos comportamentos institucionais. Os testes e a primazia das classes homogêneas são parte desse processo e marcam de forma contundente as relações entre estudantes, professores e as disciplinas. É, contudo, atrelado à produção de estatísticas de educação mais sistemáticas e de melhor qualidade que se percebe a existência, nas décadas de 1930 e 1940, do debate político-educacional sobre questões referentes ao movimento dos alunos pela escola, notadamente, sobre reprovação e evasão.

Nas décadas seguintes — 1950,1960, 1970 e 1980 -, sabe-se que a questão seguiu sendo discutida com características que interessa melhor compreender, o que motiva a continuidade das pesquisas acerca do tema. É notável, ainda, a força com que essa mesma temática volta ao debate agora, depois de mais de duas décadas (que se seguiram à Constituinte e à Constituição de 1988), período em que a ênfase na discussão educacional e na proposição das políticas para a educação tendeu ao delineamento de uma escola inclusiva e aberta à diversidade, em lugar da escola seletiva e excludente que se estabeleceu no Brasil ao longo dos séculos XIX e XX. Talvez não tenhamos ficado suficientemente atentos para o fato de que no âmbito das escolas e no debate social essa discussão não tenha ocorrido com a mesma tônica que assumiu nos meios acadêmicos e intelectuais da educação.

\section{REFERÊNCIAS}

AlmeIDA JÚNIOR, A. Repetência ou promoção automática? Revista Brasileira de Estudos Pedagógicos, Rio de Janeiro, v. 27, n. 65, p. 3-15, jan.-mar. 1957.

Besson, J-L. A ilusão das estatísticas. São Paulo: UNESP, 1995.

BouRdiEU, P. Descrever e prescrever: as condições e os limites da eficácia política. In: . A economia das trocas lingüísticas: o que falar quer dizer. 2. ed. São Paulo: EDUSP, 1998. p. 117-126.

Foucault, M. Vigiar e Punir. 10a ed. Petrópolis: Vozes, 1987.

Fouquet, A. As estatísticas no debate social. In: Besson, J-L. A ilusão das estatísticas. São Paulo: UNESP, 1995. p. 135-148.

Gallego, R. C. Usos do tempo: a organização das atividades de alunos e professores nas escolas primárias paulistas (1890-1929). São Paulo: USP, 2003. Dissertação (mestrado em Educação). Programa de Pós-Graduação em Educação, Universidade de São Paulo.

GouveiA, M. C. S. Tempos de aprender: a produção histórica da idade escolar. Revista Brasileira de História da Educação, São Paulo, n. 8, 2004, p. 265-289.

HawAT, J. L. C. Os saberes elementares matemáticos nas escolas isoladas de Porto Alegre: avaliações, programas de ensino e livros escolares (1873-1919). Porto Alegre: UFRGS, 2015. Dissertação (Mestrado em Educação). Programa de Pós-Graduação em Educação, Universidade Federal do Rio Grande do Sul.

Jacomini, M. A. Educar sem reprovar. São Paulo: Cortez, 2010. 
JinZENJi, M. Y. As escolas públicas de primeiras letras de meninas: das normas às práticas. Revista Brasileira de História da Educação, São Paulo, n. 22, p. 169-198, jan.-abr. 2010.

Kingdon, J. W. Agendas, alternatives, and public policies. New York: Harper Collins College Publishers, 1995.

Koselleck, R. Futuro passado. Contribuição à semântica dos tempos históricos, Rio de Janeiro, Contraponto/Editora PUCRio, 2006.

Lima, A. L. G.; Viviani, L. M. Conhecimentos especializados sobre os problemas de rendimento escolar: um estudo de manuais de psicologia e da Revista de Educação. História da Educação, Porto Alegre, v. 19, n. 46, p. 93-112, mai.-ago. 2015.

Lourenço Filho, M. B. A evasão escolar no ensino primário brasileiro. Revista Brasileira de Estatística, Rio de Janeiro, n. 7, p. 539-552, jul.-set. 1941.

Ministério da Educação E Saúde. O ensino no Brasil no qüinqüênio de 1932-1936. Rio de Janeiro: INEP, 1939. (Boletim n. 1)

. Situação Geral do ensino primário. Rio de Janeiro: INEP, 1941. (Boletim n. 13)

. Organização do ensino primário e normal. Estado de São Paulo. Rio de Janeiro: INEP, 1942. (Boletim n.19)

Monarcha, C. Brasil arcaico, Escola Nova: ciência, técnica e utopia nos anos 1920-1930. São Paulo: Ed. UNESP, 2009.

Patto, M. H. S. A produção do fracasso escolar. São Paulo: T.A. Queiroz, 1993.

Paulilo, A. L. A infância cercada: as políticas de controle da população escolar nas reformas educacionais do Distrito Federal entre 1922 e 1935. In: Lopes, S. C.; Chaves, M. W. (Orgs.). A história da educação em debate: estudos comparados, profissão docente, infância, família e igreja. Rio de Janeiro: Mauad X, 2012. p. 37-50.

Ribeiro, S. C. A pedagogia da repetência. Estudos Avançados, São Paulo, n. 12, v. 5, p. 7-21, 1991.

Rio Grande do Sul. Decreto n. 89, de 2 de fevereiro de 1897. Reorganisa a instrucção primaria do Estado. Leis, decretos e actos do governo do Estado do Rio Grande do Sul de 1906. Porto Alegre: Officinas Typogr. de Echenique Irmãos \& Cia, 1907.

Rocha, F. C. C. Trajetória de alunos em um grupo escolar mineiro, entre 1907 e 1916: o tema da repetência escolar. Anais do VII Congresso Brasileiro de História da Educação, Cuiabá/MT: SBHE, 2013.

Romanelli, O. O. História da educação no Brasil (1930-1973). Petrópolis: Vozes, 1978.

Saviani, D. História Das Idéias Pedagógicas No Brasil. Campinas: Autores Associados, 2007.

São Paulo. Secretaria da Educação e da Saúde Pública. Diretoria do Ensino. As reprovações na escola primária ( $\mathrm{O}$ fenômeno das reprovações. Análise das causas. Medidas contra o mal. Dados estatísticos). 1936. (Boletim n. 7)

Senra, N. C. (Org.). História das Estatísticas Brasileiras (1822-2002). Rio de Janeiro: IBGE, 2006. v. 2: Estatísticas Legalizadas (c.1889 - c.1936).

. Organizando a coordenação nacional: estatística, educação e ação política na Era Vargas. Rio de Janeiro: IBGE, 2014. 
Souza, R. F. Templos de civilização: a implantação da escola primária graduada no Estado de São Paulo (1890-1910). São Paulo: Editora da UNESP, 1998.

. Espaço da educação e da civilização: origens dos grupos escolares no Brasil. In: Saviani, D.; Almeida, J. S.; Souza, R. F.; Valdemarin, V.T. O legado educacional do século XIX. Campinas: Autores Associados, 2006. p. 33-83.

Teixeira de Freitas, M. A. Dispersão demográfica e escolaridade. Revista Brasileira de Estatística, Rio de Janeiro, n. 3, p. 497-527, jul.-set. 1940a.

. A evasão escolar no ensino primário brasileiro. Revista Brasileira de Estatística, Rio de Janeiro, v. 1, n. 4, p. 697-722, out.-dez. 1940b.

Ainda a evasão escolar no ensino primário brasileiro. Revista Brasileira de Estatística, Rio de Janeiro, v. 2, n. 7, p. 553-642, jul.-set. 1941.

\section{SOBRE A AUTORA}

Natália de Lacerda Gil é doutora em educação pela Universidade de São Paulo (USP).Professora da Universidade Federal do Rio Grande do Sul (UFRGS). E-mail: natalia.gil@uol.com.br

Recebido em 29 de março de 2016 Aprovado em 18 de outubro de 2016 